\title{
Global health care leadership development: trends to consider
}

\author{
This article was published in the following Dove Press journal: \\ Journal of Healthcare Leadership \\ 7 June 2013 \\ Number of times this article has been viewed
}

\section{Maura MacPhee' \\ Lilu Chang ${ }^{2}$ \\ Diana $\mathrm{Lee}^{3}$ \\ Wilza Spiri ${ }^{4}$}

'University of British Columbia School of Nursing, Vancouver, British

Columbia, Canada; ${ }^{2}$ Center for Advancement of Nursing Education, Koo Foundation, Sun Yat-Sen Cancer Center, Taipei, Taiwan; ${ }^{3}$ Nethersole School of Nursing, Chinese University of Hong Kong, Hong Kong, ${ }^{4}$ São Paulo State University, Botucatu, São Paulo, Brazil
Correspondence: Maura MacPhee University of British Columbia, T20I-22II Wesbrook Mall, Vancouver, British Columbia V6T2B5, Canada Tel + I 604822289 |

Fax +l 6048227466

Email maura.macphee@nursing.ubc.ca
Abstract: This paper provides an overview of trends associated with global health care leadership development. Accompanying these trends are propositions based on current available evidence. These testable propositions should be considered when designing, implementing, and evaluating global health care leadership development models and programs. One particular leadership development model, a multilevel identity model, is presented as a potential model to use for leadership development. Other, complementary approaches, such as positive psychology and empowerment strategies, are discussed in relation to leadership identity formation. Specific issues related to global leadership are reviewed, including cultural intelligence and global mindset. An example is given of a nurse leadership development model that has been empirically tested in Canada. Through formal practice-academic-community collaborations, this model has been locally adapted and is being used for nurse leader training in Hong Kong, Taiwan, and Brazil. Collaborative work is under way to adapt the model for interprofessional health care leadership development.

Keywords: health care leadership, development models, global trends, collective

\section{Introduction}

The purpose of this paper is to explore trends underway to prepare global health care leaders, and to describe leadership development models that complement these trends. Throughout the paper we offer testable propositions that we believe are fundamental considerations for developing, implementing, and evaluating global health care leadership development models and programs. Our paper is based on a variety of sources, including the health care, leadership, organizational development, and psychology literature. We begin with a brief overview of global health care leadership development trends, followed by a review of current leadership development models. We end with our own example of an empirically tested leadership development model that is being adapted to different countries and cultures (ie, Hong Kong, Taiwan, and Brazil). Although this model was originally intended for nurse leadership development, we are in the process of expanding the model for interprofessional health care leadership development. One caution: our review and our examples are drawn predominantly from Western science and practices. As authors from different cultures, we are aware of the caveats associated with unconditional acceptance of Western leadership styles and Western methodologies for leadership development and evaluation. ${ }^{1,2}$ In our collaborative work, we support (and practice) "critically reflexive cultural learning,"3 and in this paper, we advocate for leadership development strategies, such as self-reflection, participatory action learning and developmental 
evaluation, which invite new leaders to fully engage in understanding the sources for their actions, and the actions of others from within and outside their particular cultural perspectives.

\section{Global health care leadership development trends and terminology Trend I: "l" to "we"}

Leader(ship) development has traditionally focused on individuals. Day ${ }^{4}$ introduced the idea of leadership development - acknowledging that individual leaders do not have the capacity to address the challenges posed by complex health care systems. Instead, a shared, distributed, or collective approach to leadership is necessary to address complex problems with diverse perspectives, talents, and skills. Yammarino et $\mathrm{al}^{5}$ describe this trend as a shift from "I" (the leader) to "we" (shared, distributed, collective leadership). Collective leadership can occur in small and large, informal or formal groups, such as dyads, teams, units, departments, programs, systems, and networks. Although the ideal goal may be collective leadership within complex health care networks and systems, the literature suggests that leadership development begins with "I" or self-leadership competencies $^{6}$ and relational competencies associated with leading others. ${ }^{7}$

Our proposition: self-leadership and relational leadership are important precursors to collective or "we" leadership.

\section{Trend 2: globalization}

Collective leadership complements health care globalization. Globalization refers to the rapid pace by which we have become connected to each other via technology and economics. ${ }^{8}$ Health care globalization is recognized as a way to close disparity gaps and improve public health on a global scale through information and resource sharing. ${ }^{9}$ A globalization example is international "super-hospitals" that network with each other and disseminate evidence-based practices throughout their regional and local communities. These networks involve sophisticated collaborations between academic research institutions, health care organizations, and the community. Super-hospital networks have been piloted with success in Canada $^{10}$ and the USA. ${ }^{11}$

The traditional approach to global health was a flow of aid from developed countries to developing countries. New globalization trends focus on interdependencies of resourcerich and -poor countries. As Fried et al suggested:
With the new understanding that many health problems have a linked aetiology and a common impact, and that innovative solutions can come from all sectors, collaborative relationships become, at a minimum, bidirectional and optimally, multilateral. ${ }^{12}$

Earlier collaboration models focused on practiceacademic partnerships, with the community outside or exogenous to the partnership. Through a globalization lens, the community is the driver. Community engagement involves thorough knowledge of the structures and processes associated with health care resource allocation and other resources associated with the social determinants of health, such as housing. Relationships with key stakeholder groups, including the government, underpin effective practiceacademic-community collaborations. ${ }^{13}$ Building and sustaining relationships often begins in dyads and teams, progressing in complexity to networks comprised of multiple, actual, or potential collaborations. ${ }^{14-16}$ Regardless of the social configuration, collective leadership can synergize the contributions from multiple partners. ${ }^{6,17}$

Our proposition: globalization depends on complex, collaborative relationships. Collective leadership is necessary for building and sustaining global collaborations.

\section{Trend 3: interprofessional health care education meets globalization}

Health care leadership poses many challenges, beginning with how we educate health care professionals. The typical, silo-effect educational approach has made it especially difficult to provide interprofessional education, although health care is primarily delivered by teams of health care professionals. ${ }^{7}$ Collaborations hold promise for breaking down silos and promoting transformative learning. ${ }^{18}$ Learning with others increases learners' capacity to critically reason and to practically address local priorities. The Lancet report on "Health professionals for a new century"7 detailed some key academic reforms related to globalization: (a) adoption of a flexible, 21st century competency-based curricula; (b) interprofessional education to promote collaborative, non-hierarchical teamwork; (c) information technology implementation for distance education and networking; (d) local adaptation; (e) effective resource utilization, including faculty development; and (f) a new professionalism or culture based on globalization (ie, knowledge, attitudes, beliefs, and values founded on global health interdependencies). The report acknowledged that traditional academic 
institutions will have to undergo structural and process reforms to philosophically reform themselves. The Lancet report recommended, for instance, joint planning mechanisms in every country to engage key stakeholder groups, such as the government, professional associations, academic and practice communities, and the public. The report, therefore, underscored the importance of collective health care leadership and its place within interprofessional health care education.

Our proposition: global health care leaders need to be collective leaders: the learning process begins with interprofessional education.

\section{Leadership development: a potential model for global health care leaders}

After reviewing the most recent literature on leadership development, one theoretical model ${ }^{19}$ seems to be the best fit for global health care leadership trends discussed above. This multilevel model is accompanied by a variety of empirically tested strategies for developing leaders ("I") and leadership ("we"). The following section will provide an overview of the model and discuss specific levels of the model, including examples of evidence-based training approaches for each level. For the purpose of this paper, we define model as a framework to guide leadership development. Table 1 summarizes key information about each developmental level.

Day and Harrison's ${ }^{19}$ multilevel leadership identity model is based on levels of complexity and inclusiveness. Individuals first develop a sense of themselves as leaders, followed by a shift from an individual leader identity to a relational leader identity (ie, influencing others) and,

Table I Levels associated with leadership development

\begin{tabular}{|c|c|}
\hline Level & Key competencies \\
\hline \multirow[t]{3}{*}{ Self } & Self-awareness/reflection \\
\hline & Self-empowerment \\
\hline & Positive psychology/“reflected best self" \\
\hline \multirow[t]{3}{*}{ Relational } & Other-empowerment/leader \\
\hline & empowering behaviors \\
\hline & Team-building \\
\hline \multirow[t]{2}{*}{ Collective } & Collective empowerment \\
\hline & Participatory action learning \\
\hline \multicolumn{2}{|c|}{ Additional considerations } \\
\hline Organizational learning & Developmental evaluation \\
\hline \multirow[t]{3}{*}{ Collaborations } & Engagement within and across \\
\hline & boundaries (eg, boundary spanning, \\
\hline & bridging, blending) \\
\hline Culture & Cultural intelligence/global mindset \\
\hline
\end{tabular}

finally, to a collective leadership identity. To successfully accomplish the shift from "I" to "we" leadership identity, a sensitization process needs to take place at each level, which promotes a sense of the collective - how to work with others and share work, including the work of leadership. At each level trainees need to understand the broader context in which they are situated, ie, a systems approach (the individual nested in teams, nested in an organization, nested in a community, etc). Lord and Hall ${ }^{20}$ suggest that growth in leadership competence parallels changes in identity: leaders become more sophisticated and accomplished as they acquire higher levels of identity. Some research has shown that the highest level of leadership identity, collective leadership, is associated with greater moral reasoning, broader perspective-taking, and enhanced creativity and innovation. ${ }^{19}$ The developmental identity approach assumes that depending on the situation, leaders may draw on lower identity levels. Leaders, for instance, may have to be directive and take charge in crisis situations, while multiple, inclusive perspectives may enhance problem-solving when innovative thinking is desired. ${ }^{21}$ If leaders can draw upon multiple levels of identity (ie, self, relational, collective) they have a definite advantage in health care contexts with highly varied cultural and situational demands.

\section{Self-leadership identity development}

Self-development depends on the readiness of the individual to assume leadership roles and responsibilities. ${ }^{22}$ Intrinsically motivated individuals are primed to respond to "trigger events" that activate and enhance their leader identity. Trigger events can occur naturally in the practice environment, but they can also be simulated through formal training exercises and self-reflection. ${ }^{23}$ The experience of learning from successes and failures is an active process that requires self-reflection: recognizing personal and professional strengths and weaknesses. ${ }^{24} \mathrm{~A}$ critically reflective leader, therefore, is an active participant in the learning process. Other researchers refer to the "developmental readiness" of potential leaders. The hallmark of developmental readiness is an individual's willingness to accept leadership challenges. The motivation to develop leader capacity may be the best predictor of an individual's engagement in self-development over their career trajectory. ${ }^{24}$

Positive psychology highlights "those moments when we felt that our best-self was brought to light, affirmed by others and put into practice in the world., ${ }^{23}$ Positive self-reflections and feedback from others are used to construct a "reflected best self" (RBS), and the RBS serves as an anchor throughout leadership development. Looking at the "glass half-full" can 
provide a buffer against challenging and difficult situations, such as environmental and organizational "jolts" that often derail leaders. Individual RBS portraits evolve over time, and leader responses to jolts highlight the importance of the positive psychology approach with respect to outcomes. Self-aware leaders with strong RBS portraits are more likely to respond to jolts with constructive versus destructive responses. ${ }^{23,25}$ The positive psychology movement has been integrally associated with psychological empowerment strategies that enable leaders to persevere during challenging situations. $^{26}$

\section{Relational leader identity development}

Relationship-building is based on a leader's ability to foster positive work relationships among others. In health care, the focus has been on the leader's capacity to sculpt and support high-performing clinical and administrative teams (eg, clinical or direct care delivery, and front-line, midlevel, executive administrative levels). ${ }^{27}$ The literature is replete with instruction on team-building and there are many theoretical models and accompanying tools to assess how individual leaders perform within teams. ${ }^{28-30}$ The leadermember exchange (LMX) theory focuses on the quality of relationships or exchanges between an individual leader and team members. Effective leader-member exchanges result in such things as higher levels of team performance and organizational citizenship behaviors. ${ }^{31}$ LMX theory may be a stepping stone for collective leadership as leaderfollower interactions evolve over time, from individual self-interests to shared interest based on trust, respect, and interdependencies. ${ }^{32}$

Teams are the basic functional units of health care organizations, and the development of relational and collective leadership competencies often takes place within teams. ${ }^{28,33}$ Transition to collective team leadership may depend on developing shared mental models that enable team members to recognize and respond to similar, critical elements in their environment. ${ }^{33}$ Many team training programs facilitate the development of shared mental models, ${ }^{34}$ and quality and safety initiatives emphasize the importance of shared mental models with respect to team effectiveness. ${ }^{35}$ It is very likely that shared mental models also enhance transference of leadership roles and actions among team members. ${ }^{16,36}$

To facilitate a shift to "we" within teams, selection criteria for teams may include individual characteristics such as collective orientation or preference for working with others. ${ }^{37}$ Individuals who are skilled at empowering others may be selected to seed or prime the team for effective sharing of leadership responsibilities. ${ }^{38}$ A meta-analysis of leader behaviors in teams showed that leader empowering behaviors accounted for $30 \%$ of the variance in team learning. ${ }^{28}$ There are five categories of leader empowering behaviors: (a) enhancing meaningfulness of work; (b) fostering participation in decision-making; (c) facilitating goal accomplishment; and (d) providing autonomy and freedom from bureaucratic restraints. ${ }^{39}$ These behaviors are trainable, and there is evidence that these behaviors are precursors to employee job satisfaction, productivity, and organizational commitment. $^{40}$

Day et $\mathrm{al}^{30}$ expanded on the classic input-process-output model to acknowledge the dynamic and cyclical nature of how "I" leadership can shift to "we" leadership within teams. In their I (input) M (mediational influence) $\mathrm{O}$ (outcomes) I (input) model (IMOI), individual team member contributions are gradually assimilated and processed as "we" teamwork, and team learning. Teamwork and team learning mediate the relationship between individual team member inputs and eventual team leadership capacity. Over time, team members become more connected, more interdependent and more capable of sharing leadership roles and responsibilities for the sake of the team: in this way there is a shift from individual human capital to team social capital.

Although relational leader competencies may be integral to collective leadership development, we want to emphasize that team leadership training should also include key taskfocused competencies, such as knowing how to compose an effective team (eg, size, diversity, skills), and how to design the task with a common compelling purpose, a clear direction and goals, and appropriate organizational supports and resources. ${ }^{28}$ In today's complex health care environments, leaders and leadership require expertise in both relational and task competencies. ${ }^{41}$

\section{Collective leadership identity development}

Participatory action learning is one strategy associated with team learning and collective leadership development. This strategy has been successfully used in business and management and in health care, psychology, and social sciences to build communities of practice through community engagement and collective empowerment. ${ }^{42-45}$ Participatory action learning typically focuses on building confidence and giving all parties, particularly under-represented or marginalized parties, more of a voice. In these instances, action learning is used to raise people's awareness of their 
collective power and mobilize that power through collective action. ${ }^{44,45}$ In a case study on leadership development in one US organization, project team action learning was used to increase leadership capacity. ${ }^{46}$ Team members were asked at the start of the project to focus on carrying out the task collectively, versus relying on an individual leader to direct team actions. Enhanced leadership capacity was attributed to members' efforts to consciously seek out and develop new relationships within and beyond their team, that is, to create a network of relationships. ${ }^{46}$

The action learning literature is closely aligned with empowerment strategies that, interestingly, parallel leadership identity levels. Self-empowerment, for instance, is intended to strengthen how individuals think about themselves, to master their own capacity to make a difference. ${ }^{47}$ Empowering others is similar to relational identity whereby an individual, such as a leader, focuses on raising others' awareness of their personal power through empowerment strategies. ${ }^{48,49}$ Collective empowerment refers to strategies that maximize power through collective action, and action learning can serve as a mechanism for inducing collective leadership and collective empowerment.

Our proposition: the developmental identity model, participatory action learning and empowerment strategies support leaders' growing sophistication and inclusivity as they transition from self, to relational, to collective leadership identities. The team context serves as an excellent learning medium for "I" to "we" leadership development.

\section{Multilevel leadership development within organizations}

Leadership development needs to be a sustained process over time whereby leaders learn how to collectively lead, or to think of the "we" versus the "I." Learning organizations are associated with cultures that promote continuous employee learning and leadership development. ${ }^{50}$ Although physical space and other material resources are necessary for organizational learning, ${ }^{51}$ psychological space refers to employees' perceptions that they can openly share information and ideas with each other. ${ }^{52,53}$ Sharlow et $\mathrm{al}^{54}$ describe how they promoted a learning culture within one health care organization by using a positive psychology approach as their guiding philosophy. The design and implementation of the project was based on Wenger's community of practice (CoP) principles. ${ }^{55}$ Communities of practice connect individuals with a common purpose or shared vision. In the Sharlow et al example, ${ }^{54} \mathrm{CoPs}$ consisted of cohorts from different organizational levels (eg, executive directors, operations leaders). Each learning cohort had similar accountabilities, and participants identified several advantages to peer-based CoPs, such as increased peer collaboration, trust, and networking opportunities. Peerbased learning cohorts met three times a year to receive new didactic content and engage in discussions related to their level within the organization. Although the original plan had been to mix participants from different organizational levels, attendees were concerned about revealing role weaknesses with supervisors and subordinates (raising the issue of trust formation). MacPhee et $\mathrm{al}^{56}$ found that novice front-line nurse leaders preferred peer-based learning, while mid-level leaders seemed comfortable learning with leaders from other health care disciplines or organizational levels. The front-line nurse leaders, newer to their roles, may have needed more psychological space than leaders at higher organizational levels who were accustomed to interacting with other disciplines and other leadership levels.

Many organizations view leadership development as a program or initiative that is "someone else's job" versus the real work of the organization. Learning organizations invest in leadership as an unfolding process - rather than viewing leaders as individuals with static job positions and titles. ${ }^{57,58}$ In a qualitative interview study on health care leadership development in the USA, ${ }^{59} 160$ key-informant interviews were conducted to produce a list of exemplary health care leadership development practices within organizations. In addition to an organizational "development mindset" to support a continuum of leadership learning, other best practices included practice-academic collaborations to build internal leadership development programs suited to organizational needs, carefully planned organization-wide metrics to justify organizational investment in leadership development, and codevelopment of administrators and clinicians. Organizational learning also requires continual assessment of leadership learning needs, and developmental evaluation approaches are particularly well-suited to organizational multilevel leadership development. ${ }^{60-62}$ With respect to collective leadership within teams, for instance, developmental evaluation prompts members to critically assess how leadership is being shared and how team goals are being met.

Social network research has shown how leadership capacity grows within organizations that encourage individuals to increase their scope of influence by connecting within and across organizations. ${ }^{62}$ Based on a team context, boundary-spanning refers to activities across different teams and bridge-making involves efforts within teams to bridge differences (eg, cultural, linguistic) between members. 
Another related term is "blending" subgroups within teams. ${ }^{38,62-65}$ Research on boundary spanning in virtual teams $^{64}$ and multinational teams ${ }^{66}$ indicates that effective boundary spanners are often formal leaders who are trusted by their teams and who do not prioritize the importance of one team over another. Similarly, effective bridge makers support team efforts and reward teams (versus individuals), and also facilitate intra-team communications and collaboration.

Our proposition: organizational leadership development requires a learning culture that continually assesses its learning needs using strategies, such as developmental evaluation, and promotes psychological space for learning within and across organizational boundaries.

\section{Global leadership development}

Cultural differences can lead to team dysfunction. ${ }^{67}$ In one study on multinational teams with leaders from North America, People's Republic of China, Japan, and Australia, successful team outcomes depended on careful team structuring: work teams were mixes of cross-cultural and cross-functional teams that used collaborative approaches for determining work strategy. ${ }^{68}$ To avoid potential conflict, team members represented all cultures, strategic functions, and organizational levels. The team also included a "transcultural" insider with comfort working across cultures, and a consultant who served as a facilitator. The diverse mix enabled teams to uncover potential cultural conflicts and construct new ways of working collaboratively across cultural differences. Relationship-building skills were essential components to bridging cultural differences. Relationship-building is necessary to reveal the deeper roots of cultural differences so that teams can openly acknowledge deeper differences and collaboratively address these differences. ${ }^{68}$ Traditional team management approaches often minimize team member diversity to avoid coordination and communication difficulties. ${ }^{69}$ Diversity, however, can be a team's most valuable resource for recognizing and bridging cultural differences and spurring multicultural innovation. ${ }^{69}$ Collective leadership strategies, such as participatory action learning and developmental evaluation, may provide richer opportunities for promoting global, multicultural relationships and teamwork.

In some cultures, individuals prefer directive versus participatory approaches, and they expect a leader to take control. ${ }^{64}$ In fact, in some cultures, leader empowering behaviors and a shift from "I" to "we" leadership results in loss of leader legitimacy. "I" leadership may be a necessary condition in some cultures until trust and respect have been earned, and collective leadership can be gradually introduced. Shifting culture towards collective leadership involves slow assimilation of sharing power and leadership responsibilities. Zander and Butler ${ }^{64}$ created a leadership matrix based on the degree of vertical versus horizontal (shared) authority and the degree of focused leader decision-making versus distributed decision-making. The four predominant leadership styles in this matrix are: single leadership (vertical, focused), paired or co-leadership (horizontal, focused), rotated leadership (vertical, distributed) and shared leadership (horizontal, distributed). Individual leadership works best in cultures that value vertical formal authority and task-focused leaders. To "smooth" the way to shared leadership, paired or co-leader models introduce the concept of shared power where both leaders remain task-focused while learning how to make decisions together. Over time, the introduction of rotated leadership enables team members to rotate formal decision-making responsibilities, building competencies among all the members. Vertical leader authority is not shared but rotated so that individual members rotate responsibility for making decisions. Hierarchy-based rotated leadership among junior and senior team members is fairly common in health care disciplines, and other disciplines where rank and delegation are a part of cultural beliefs, values and norms. ${ }^{70}$ With shared leadership, a formal authority structure is absent and team members are acculturated to value collective or shared decision-making. ${ }^{70-72}$ Many health care team training programs, such as the US TeamSTEPPS program, ${ }^{73}$ are based on collaborative communications and decision-making. Research with TeamSTEPPS has demonstrated its effectiveness in developing and maintaining superior team performance and effectiveness in diverse health care settings. ${ }^{74,75}$

Global mindset refers to how we think about globalization. At the individual level, global mindset refers to an individual leader's comfort with multiple cultural influences. ${ }^{76}$ Global mindset is a "way of being" that encompasses cultural intelligence (CQ). ${ }^{77,78}$ Cultural intelligence and global mindset require cultural awareness and skills associated with intercultural empathy. ${ }^{78}$ There is limited research on $\mathrm{CQ}$, although one study ${ }^{79}$ found that in culturally diverse teams, leader CQ contributed to team member perceptions of enhanced leader and team performance. More research in different global contexts is needed to determine if contemporary team-building strategies (eg, TeamSTEPPS), coupled with CQ, will result in enhanced team effectiveness.

Our proposition: global health care leadership development depends on a careful assessment of the current leadership 
culture with incremental shifts towards collective leadership. By working collaboratively within and across cultures, we can "grow" cultural intelligence.

\section{Our leadership development example}

We will conclude our paper with a brief overview of an empirically tested, Canadian nurse leadership development model that we have been culturally adapting for front-line (clinical) and mid-level (director) nurse leader education in Hong Kong, Taiwan, and Brazil. We are gradually expanding the model for interprofessional health care leadership development. Our collaborative work is based on strong practice-academic-community partnerships that are steadily growing through concerted relationshipbuilding and networking efforts. Model adaptation has followed the evidence-based propositions put forth in this paper, and we are using a variety of evaluation strategies, including developmental evaluation, to formally test our propositions.

A full description of the Canadian model and its formal evaluation are presented in other, published papers. ${ }^{56,80-83}$ The Canadian model is based on the leadership identity approach where leaders first learn self-leadership competencies followed by relational team competencies and collective team competencies. The learning modules are titled: Leading self, Leading others, Leading change through effective teamwork, and Leading teams within complex organizations. Although training begins with "I" leadership, throughout the program, participants are sensitized to the importance of "we" leadership. The model also has an overarching empowerment framework that emphasizes the theoretical roots and practice applications for self-empowerment, other-empowerment and collective empowerment strategies. Associated competencies, such as team-building, are incorporated throughout the modules. Training is based on pedagogical ideals for leadership development: an educational workshop that utilizes participatory action learning strategies, such as case-based discussions and problem-solving; a year-long innovation project of relevance to leaders' respective organizations; and mentorship support from within the organizations, typically at higher leadership levels. Implementation of these components has varied by country, often based on available resources and learning needs.

In Hong Kong we are inaugurating (April 2013) a Chinese University of Hong Kong and University of British Columbia Nurse Leadership Development Center.
It will serve as: (a) a development center for nurse leaders at different administrative levels; (b) a knowledge center for generating and translating research evidence to guide leadership practice; and (c) a network base for local, national, and international leadership collaborations. Hong Kong has over 40,000 nurses and 20\% are in leadership positions. The Chinese University of Hong Kong is also engaged in many formal partnerships with lower mainland People's Republic of China. This center, therefore, is recognized for its revenue-generating potential and is strongly endorsed by the academic and practice communities and the government. In Taiwan, we held our first leadership development pilot at Koo Foundation Sun YatSen Cancer Center (KFSYSCC) for 54 novice front-line nurse leaders from 14 medical centers surrounding Taipei. The pilot was funded through KFSYSCC with support from the Department of Health, The National Union of Nurse Associations, and nurse faculty from National Taiwan University School of Nursing. We are in the process of psychometrically validating culturally adapted leadership assessment tools, and we are expanding the curriculum to offer an interprofessional health care leader program in 2013. In Brazil, formal collaborations are currently being forged, and our plan is to pilot the model for novice nurse leaders in 2014.

To conclude, there are many obstacles to global health care leadership development, such as silo-style disciplinary training, lack of organizational support, and cultural differences. Strategies such as critical self-reflection, participatory action learning and developmental evaluation are particularly important for highlighting cultural differences and avoiding post-colonial tendencies to Westernize leadership development in non-Western health care environments. We believe that current trends, as cited at the beginning of this paper, are enabling us to innovatively move forward with global health care leadership development. We hope that the propositions promulgated throughout this paper will serve as a foundation for model development and testing in diverse global contexts.

\section{Disclosure}

The authors of this manuscript declare no conflict of interest with the development or the content of this manuscript.

\section{References}

1. Westwood R. International business and management studies as an orientalist discourse: a postcolonial critique. Critical Perspectives on International Business. 2006;2:91-113.

2. Westwood R, Jack G. Manifesto for a post-colonial international business and management studies: a provocation. Critical Perspectives on International Business. 2007;3:246-265. 
3. Witte AE. The global awareness curriculum in international business programs: a critical perspective. Journal of Teaching in International Business. 2010;21:101-131.

4. Day D. Leadership development: a review in context. Leadersh $Q$. 2000;11:581-613.

5. Yammarino F, Salas E, Serban A, Shirreffs K, Shuffler M. Collectivistic leadership approaches: putting the "we" in leadership science and practice. Ind Organ Psychol. 2012;5:382-402.

6. Neck C, Houghton J. Two decades of self-leadership theory and research: past developments, present trends, and future possibilities. Journal of Managerial Psychology. 2006;21:270-295.

7. Frenk J, Chen L, Bhutta Z, et al. Health professionals for the new century: transforming education to strengthen health systems in an interdependent world. Lancet. 2010;376(9756):1923-1958.

8. MacLeod S. Hospitals and academic health sciences centres: leaders or followers in health globalization? Healthc Pap. 2003;4:64-68.

9. Sachs JD. Macroeconomics and Health: Investing in Health for Economic Development. Report to the World Health Organization of the Commission on Macroeconomics and Health. Geneva: World Health Organization; 2001. Available from: http://www.cid.harvard. edu/archive/cmh/cmhreport.pdf. Accessed April 25, 2013.

10. Brazil K, MacLeod S, Guest B. Collaborative practice: a strategy to improve the relevance of health services research. Healthc Manage Forum. 2002;15:18-24.

11. Raymond S, Greenberg H. Playing to strength-Downstate's emerging urban specialization. In: Raymond S, Greenberg H, editors. Medical Education and Clinical Research in the 21st Century. New York: Academy of Sciences, Sciences and Technology Program Special Report; 2000:29.

12. Fried L, Bentley M, Buekens P, Burke D, Frenk J, Klag M. Global health is public health. Lancet. 2010;375:535-537.

13. Community Engagement Key Function Committee Task Force. Principles of Community Engagement, 2nd ed. National Institute of Health Publication No 11-7782; 2011.

14. Bono J, Anderson M. The advice and influence networks of transformational leaders. J Appl Psychol. 2005;90:1306-1314.

15. DeChurch L, Burke C, Shuffler M, Lyons R, Doty D, Salas E. A historiometric analysis of leadership in mission critical multi-team environments. Leadersh Q. 2011;22:152-169.

16. Hernandez M, Eberly M, Avolio B, Johnson M. The loci and mechanisms of leadership: exploring a more comprehensive view of leadership theory. Leadersh Q. 2011;22:1165-1185.

17. Kania J, Kramer M. Collective impact. Stanford Social Innovation Review. 2011; Winter:36-41.

18. Mezirow J. Learning as Transformation: Critical Perspectives on a Theory in Progress. San Francisco: Jossey Bass; 2000.

19. Day D, Harrison M. A multilevel, identity-based approach to leadership development. Human Resource Management Review. 2007;17: 360-373.

20. Lord R, Hall R. Identity, deep structure, and the development of leadership skill. Leadersh Q. 2005;16:591-615.

21. Yun S, Faraj S, Sims H. Contingent leadership and effectiveness of trauma resuscitation teams. J Appl Psychol. 2005;90:1288-1296.

22. Avolio B, Walumbwa F, Weber T. Leadership: current theories, research, and future directions. Annu Rev Psychol. 2009;60:421-429.

23. Roberts L, Dutton J, Spreitzer G, Heaphy E, Quinn R. Composing the reflected best-self portraits: building pathways for becoming extraordinary in work organizations. Acad Manage Rev. 2005;30:712-736.

24. Reichard R, Johnson S. Leader self-development as organizational strategy. Leadersh Q. 2011;22:33-42.

25. Hannah S, Woolfolk R, Lord R. Leader self-structure: a framework for positive leadership. J Organiz Behav. 2009;20:269-290.

26. Spreitzer G. Taking stock: a review of more than twenty years of research on empowerment at work. In: Cooper C, Barling J, editors. The Handbook of Organizational Behavior. Thousand Oaks, CA: Sage Publications; 2007:54-72.
27. Baker D, Day R, Salas E. Teamwork as an essential component of high reliability organizations. Health Serv Res. 2006;41:1576-1598.

28. Burke CS, Stagl K, Klein C, Goodwin G, Salas E, Halpin S. What types of leadership behaviors are functional in teams? A meta-analysis. Leadersh Q. 2006;17:288-307.

29. Wageman R, Hackman R, Lehman E. Team diagnostic survey: development of an instrument. J Appl Behav Sci. 2005;41:373-398.

30. Day D, Gronn P, Salas E. Leadership capacity in teams. Leadersh $Q$. 2004; $15: 857-880$.

31. Ilies R, Nahrgang J, Morgeson F. Leader-member exchange and citizenship behaviors: a meta-analysis. J Appl Psychol. 2007;92: 269-277.

32. Uhl-Bien M, Graen G, Scandura T. Implications of leader-member exchange (LMX) for strategic human resource management systems: relationships as social capital for competitive advantage. Res Pers Hum Resour Manage. 2000;18:137-185.

33. Decuyper S, Dochy F, Van den Bossche P. Grasping the dynamic complexity of team learning: An integrative model for effective team learning in organisations. Educational Research Review. 2010;5: 111-133.

34. Mathieu J, Heffner T, Goodwin G, Salas E, Cannon-Bowers J. The influence of shared mental models on team process and performance. J Appl Psychol. 2000;85:273-283.

35. Kunzle B, Kolbe M, Grote G. Ensuring patient safety through effective leadership behaviour: A literature review. Saf Sci. 2010;48:1-17.

36. Burke CS, Fiore S, Salas E. The role of shared cognition in enabling shared leadership and team adaptability. In: Pearce C, Conger J, editors. Shared leadership: Reframing the Hows and Whys of Leadership. Thousand Oaks, CA: Sage; 2003:117-134.

37. Salas E, Sims DE, Burke CS. Is there a "Big Five" in teamwork? Small Gr Res. 2005;36:555-599.

38. Marrone J. Team boundary-spanning: a multilevel review of past research and proposals for the future. J Manage. 2010;36:911-940.

39. Hui C. Effects of Leader Empowerment Behaviors and Followers' Personal Control, Voice and Self-efficacy on In-Role and ExtraRole Performance: An Extension and Empirical Test of Conger and Kanungo's Empowerment Process Model [dissertation]. Proquest Information and Learning UMI No 9418834;1994.

40. Greco P, Laschinger H, Wong C. Leader empowering behaviours, staff empowerment and work engagement/burnout. Can J Nurs Leadersh. 2006;19:41-56.

41. Derue S, Nahrgang J, Wellman N, Humphrey S. Trait and behavioural theories of leadership: An integration and meta-analytic test of their relative validity. Pers Psychol. 2011;64:7-52.

42. Edmonstone J. Action learning and organization development: overlapping fields of practice. Action Learning, Research and Practice. 2011;8:93-102.

43. Marquardt M. Action Learning: Solving Problems and Building Leaders in Real Time. Palo Alto, CA: Davies-Black; 2004.

44. Butterfoss F. The coalition technical assistance and training framework: helping community coalitions help themselves. Health Promot Pract. 2004;5:118-126.

45. Aber M, Maton K, Seidman E. Empowering Settings and Voices for Social Change. Oxford: Oxford University Press; 2011.

46. Van Velsor E, McCauley C. Our view of leadership development. In: McCauley C, Van Velsor E, editors. The Center for Creative Leadership Handbook of Leadership Development, 2nd ed. San Francisco, CA: Jossey-Bass; 2004:1-22.

47. Akerjordet K, Severinsson E. Emotionally intelligent nursing leadership: a literature review study. J Nurs Manage. 2008;16:565-577.

48. Kanter R. Men and Women of the Corporation. New York: Basic Books; 1993.

49. Spreitzer G. Psychological empowerment in the workplace: dimensions, measurement and validation. Acad Manage J. 1995;38:1442-1465.

50. Amagoh F. Leadership development and leadership effectiveness. Management Decision. 2009;47:989-999. 
51. Berwick D. Disseminating innovations in health care. JAMA. 2003;289: 1969-1975.

52. Kolb A, Kolb D. Learning styles and learning spaces: enhancing experiential learning in higher education. Academy of Management Learning and Education. 2005;4:193-212.

53. Day D. Being there even when you are not: leading through strategy, structures and systems. Monographs in Leadership and Management. 2007;4:13-30.

54. Sharlow J, Langenhoff P, Bhatti A, Spiers J, Cummings G. Learning together: a cohort approach to organizational leadership development. Leadersh Health Serv (Bradf Engl). 2009;22:317-328.

55. Wenger E, McDermott R, Snyder W. Cultivating Communities of Practice: A Guide to Managing Knowledge. Boston, MA; Harvard Business School Press: 2002.

56. MacPhee M, Skelton-Green J, Bouthillette F, Suryaprakash N. An empowerment framework for nursing leadership development: supporting evidence. JAdv Nurs. 2011;68:159-169.

57. Leskiw S-L, Singh P. Leadership development: learning from best practice. Leadership and Organization Development Journal. 2007;28: 444-464.

58. Green M. Ensuring the organization's future: a leadership development case study. Public Pers Manage. 2003;31:431-439.

59. McAlearney AS. Exploring mentoring and leadership development in health care organizations: Experience and opportunities. Career Development International. 2005;10:493-511.

60. Gamble J. A Developmental Evaluation Primer. Montreal: JW McConnell Family Foundation; 2008.

61. Patton MQ. Developmental Evaluation: Applying Complexity Concepts to Support Innovation and Use. Thousand Oaks, CA: Sage; 2011.

62. Watkins K, LysØ I, DeMarrais K. Evaluating executive leadership programs: A theory of change approach. Advances in Developing Human Resources. 2011;13:208-239.

63. Kilduff M, Tsai W. Social Networks and Organizations. Thousand Oaks, CA; Sage: 2003.

64. Zander L, Butler C. Leadership modes: success strategies for multicultural teams. Scandinavian Journal of Management. 2010;26: 258-267.

65. Butler C, Zander L, Mockaitis A, Sutton C. The global leader as boundary spanner, bridge maker and blender. Ind Organ Psychol. 2012;5:240-243.

66. Joshi A, Lazarova M. Do global teams need global leaders? Identifying leadership competencies in multinational teams. In: Shapiro D, editor, Managing Multinational Teams: Global Perspectives. Amsterdam: Elsevier; 2005:281-301.

67. Graen G, Hui C, Gu Q. A new approach to intercultural cooperation. In: Graen G, editor. New Frontiers of Leadership, LMX Leadership, 2nd ed. Greenwich, CT: Information Age Publishing; 2004:225-246.
68. Graen G. In the eye of the beholder: cross-cultural lesson in leadership from project GLOBE: a response viewed from the third culture bonding model of cross-cultural leadership. Academy of Management. 2006;20: 95-101.

69. McDaniel R, Walls M. Diversity as a management strategy for organizations: A view through the lenses of chaos and quantum theories. Journal of Management Inquiry. 1997;6:363-375.

70. Klein K, Ziegert J, Knight A, Xiao Y. Dynamic delegation: shared, hierarchical and deindividualized leadership in extreme action teams. Administrative Science Quarterly. 2006;51:590-621.

71. Carson J, Tesluk P, Marrone J. Shared leadership in teams. An investigation of antecedent conditions and performance. Acad Manage J. 2007;50:1217-1234.

72. Pearce C, Manz C, Sims H. Where do we go from here? Is shared leadership the key to team success? Organ Dyn. 2009;38:234-238.

73. Clancy C, Tornberg D. Team STEPPS: Assuring optimal teamwork in clinical settings. AM J Med Qual. 2007;22:214-217.

74. Mayer C, Cluff L, Wei-Ting L, et al. Evaluating efforts to optimize TeamSTEPPS implementation in surgical and pediatric intensive care units. Joint Comm J Qual Im. 2011;37:365-374.

75. Thomas L, Galla C. Building a culture of safety through team training and engagement. BMJ Qual Saf. doi:10.1136/bmjqs-2012-001011

76. Levy O, Beechler S, Taylor S, Boyacigiller N. What we talk about when we talk about global mindset: Managerial cognition in multinational corporations. Journal of International Business Studies. 2007;38: 231-258.

77. Earley C, Ang S. Cultural Intelligence: Individual Interactions Across Cultures. Palo Alto, CA; Stanford University Press: 2003.

78. Early C, Murnieks C, Mosakowski E. Cultural intelligence and the global mindset. In: Javidan M, Steers R, Hitt M, editors. The Global Mindset. New York: Elsevier; 2007:75-103.

79. Groves K, Feyerherm A. Leader cultural intelligence in context: Testing the moderating effects of team cultural diversity on leader and team performance. Group and Organization Management. 2011;36: $535-566$.

80. MacPhee M, Bouthillette F. Developing leadership in nurse managers: The British Columbia Nursing Leadership Institute. Can J Nurs Leadersh. 2008;21:65-75.

81. MacPhee M, Dahinten V, Hejazi S, et al. Testing the effects of an empowerment-based leadership development programme: part 1-leader outcomes. J Nurs Manage. Epub 2013 May 8.

82. Dahinten V, MacPhee, M, Hejazi S, et al. Testing the effects of an empowerment-based leadership development programme: part 2-staff outcomes. J Nurs Manage. 2013. In press.

83. MacPhee M, Suryaprakash N. First-line nurse leaders' health-care change management initiatives. J Nurs Manage. 2012;20:249-259.
Journal of Healthcare Leadership

\section{Publish your work in this journal}

The Journal of Healthcare Leadership is an international, peer-reviewed, open access journal focusing on leadership for the health profession. The journal is committed to the rapid publication of research focusing on but not limited to: Healthcare policy and law; Theoretical and practical aspects healthcare delivery; Interactions between healthcare and society and evidence-based practices;

\section{Dovepress}

Interdisciplinary decision-making; Philosophical and ethical issues; Hazard management; Research and opinion for health leadership; Leadership assessment. The manuscript management system is completely online and includes a very quick and fair peer-review system. Visit http://www.dovepress.com/ testimonials.php to read real quotes from published authors. 